\title{
Mental health among UK inner city non-heterosexuals: the role of risk factors, protective factors and place
}

\author{
C. Woodhead*t, B. Gazardt, M. Hotopf, Q. Rahman, K. A. Rimes and S. L. Hatch \\ Psychological Medicine, Institute of Psychiatry, Psychology and Neuroscience, King's College London, London, UK
}

\begin{abstract}
Background. Sexual minorities experience excess psychological ill health globally, yet the UK data exploring reasons for poor mental health among sexual minorities is lacking. This study compares the prevalence of a measure of well-being, symptoms of common mental disorder (CMD), lifetime suicidal ideation, harmful alcohol and drug use among inner city non-heterosexual and heterosexual individuals. It is the first UK study which aims to quantify how much major, everyday and anticipated discrimination; lifetime and childhood trauma; and coping strategies for dealing with unfair treatment, predict excess mental ill health among non-heterosexuals. Further, inner city and national outcomes are compared.
\end{abstract}

Methods. Self-report survey data came from the South East London Community Health study $(N=1052)$ and the Adult Psychiatric Morbidity Survey $(N=7403)$.

Results. Adjustments for greater exposure to measured experiences of discrimination and lifetime and childhood trauma had a small to moderate impact on effect sizes for adverse health outcomes though in fully adjusted models, non-heterosexual orientation remained strongly associated with CMD, lifetime suicidal ideation, harmful alcohol and drug use. There was limited support for the hypothesis that measured coping strategies might mediate some of these associations. The inner city sample had poorer mental health overall compared with the national sample and the discrepancy was larger for non-heterosexuals than heterosexuals.

Conclusions. Childhood and adult adversity substantially influence but do not account for sexual orientation-related mental health disparities. Longitudinal work taking a life course approach with more specific measures of discrimination and coping is required to further understand these associations. Sexual minorities should be considered as a priority in the design and delivery of health and social services.

Received 15 May 2015; Accepted 6 July 2015; First published online 12 August 2015

Key words: Cross cultural psychiatry, discrimination, epidemiology, mental health, minority issues.

\section{Introduction}

Sexual minority status is linked to an excess burden of poor mental health. Available research suggests that individuals identifying as lesbian, gay and bisexual (LGB) or 'non-heterosexual' are at two-fold excess risk of suicide attempts and experience approximately 1.5 greater odds of depression, anxiety and substance abuse (Cochran et al. 2003; King et al. 2008). Minority stress theory proposes that this is due to discrimination, victimisation, social exclusion and marginalisation associated with stigmatised identity status (Meyer, 2003; Herek \& McLemore, 2013). Other key

* Address for correspondence: Dr Charlotte Woodhead, Department of Applied Health Research, 1-19 Torrington Place, London, WC1E 7HB.

(Email: c.woodhead@ucl.ac.uk)

† Joint first author. risk factors include childhood and lifetime exposure to sexual and physical abuse (Friedman et al. 2011). While such exposure is a risk factor for poor mental health in general, the rates are significantly higher among sexual minorities than heterosexual populations (Balsam et al. 2005; Austin et al. 2008). These external factors may cascade into disrupted psychological mechanisms and resources such as coping, emotion regulation, rumination and other cognitive processes, and reduced interpersonal or social functioning resulting in mental ill-health (Meyer, 2003; Hatzenbuehler, 2009). Studies of mental health disparities between heterosexual and LGB individuals in the UK are rare. One nationally representative study of England reported non-heterosexuals to have approximately 1.5 to 2.8 -fold greater odds of neurotic disorders, drug and alcohol dependence, lifetime suicidal thoughts and attempts (Chakraborty et al. 2011). Very few UK or European studies have directly quantified 
the underlying minority stress and other mechanisms for sexual orientation-related mental health disparities though available findings support those from US studies. A recent UK longitudinal study found that early victimisation partially explained emotional distress disparities in LGB young people (Robinson et al. 2013) and other minority stress mechanisms involving negative experiences of 'coming out' and homophobic bullying have been associated with increased odds of suicidal thoughts and attempts (Nodin et al. 2015). The UK attitudes towards homosexuality have become increasingly tolerant; however, experiences of homophobia and victimisation remain common (Guasp, 2012; Guasp et al. 2013). London is notable for its cultural diversity and resident to the highest proportion of non-heterosexuals across the UK, likely due to the inward migration of non-heterosexuals (Greater London Authority (GLA), 2011; Office for National Statistics (ONS), 2013). Living in areas with a higher concentration of sexual minority individuals may be protective against common mental disorders (Hatzenbuehler et al. 2011), thus discrepancies in mental health may be less apparent.

This study aims to estimate the proportion of inner city individuals identifying themselves as nonheterosexual using data from the South East London Community Health Survey (SELCoH) and to quantify the impact of putative risk factors on the rates of mental disorders and substance misuse associated with sexual orientation. Four hypotheses will be tested: (1) mental ill-health and substance use will be elevated among the non-heterosexual group; (2) exposure to discrimination and childhood/lifetime trauma will account for some of this excess morbidity; (3) differences in coping strategies will mediate the association between sexual orientation and health outcomes; and (4) excess risk of poor mental health and substance misuse found will be lesser in the inner city than the national sample.

\section{Methods}

The SELCoH study is a survey of randomly selected households in the South East London (Southwark and Lambeth). The survey assesses demographic and socio-economic characteristics; physical and mental health symptoms; treatment and service use; social adversity; and psychosocial resources. Participation in SELCoH was in line with that in similar national surveys for example, Adult Psychiatric Morbidity Survey (APMS) (McManus et al. 2009) and the sample was broadly representative of the local population on core demographic characteristics (Hatch et al. 2011).

Detailed information about the recruitment procedures has previously been reported (Hatch et al.
2011, 2012) and followed the format used by the APMS. The first phase (SELCoH I) took place between June 2008 and December 2010 and the second phase (SELCoH II) targeted 1596 (94\%) of the participants who agreed to be re-contacted from August 2011 to March 2013. Addresses were randomly sampled from the Small User Postcode Address File. Letters describing the study were sent to all private households inviting those aged over 16 years to participate.

SELCoH I included 1698 adults from 1075 households (household response rate: 51.9\%, withinhousehold participation rate: $71.9 \%$ ); In SELCOH II, interviews were conducted with 1052 participants (response rate $73 \%$ ) using a computer assisted interview schedule; 1022 were face-to-face interviews in their households and 30 (2.9\%) interviews were conducted using Computer Assisted Telephone Interviews to access participants who were temporarily located outside of London during the data collection. Unless otherwise stated the current analyses refer to data from SELCOH II. APMS data were retrieved from the UK Data Archive; use of the data for the purposes of comparison with SELCoH was recorded.

\section{SELCoH measures}

\section{Sexual orientation}

Sexual orientation was assessed with the question, 'Please choose the answer that best describes how you think of yourself. .' response categories were 'heterosexual (straight)', 'homosexual (gay)', 'bisexual' or 'other'. Due to small numbers a binary 'heterosexual/ non-heterosexual (including 'other')' variable was created for analyses as is typical for population-level research with sexual minorities (Cochran et al. 2003; King et al. 2008).

\section{Demographic and socio-economic characteristics}

Ethnicity (recoded non-white, white), country of birth (recoded the UK, non-UK), age, relationship status, educational qualifications, religion (recoded agnostic/ atheist/none, any other), self-reported gross monthly individual income (quintiles), employment status and household tenure were recorded. Gender was also recorded (no participants identified as transgender).

\section{Experiences of discrimination}

Major experiences of discrimination (Williams et al. 1997) were assessed by asking whether participants had ever been treated unfairly in a list of 12 situations (e.g., being fired), and how many times this had happened. Responses were dichotomised ('never' $v$. 'ever'). Those ever reporting any of the 12 domains 
were also identified. Everyday discrimination (Kessler et al. 1999) was evaluated with ten items beginning with the stem, 'things that may happen in your day-to-day life' (e.g., being called names or insulted). Responses were recorded on a five-point scale ranging from 'never' to 'very often'. Each item was dichotomised distinguishing those recorded as 'fairly/very' often from less frequent experiences. Those reporting ever experiencing each domain were summed over all domains. A binary variable was created around the median number of domains endorsed. Anticipated discrimination items were taken from the Discrimination and Stigma Scale (Thornicroft et al. 2009), which was amended to assess the extent to which participants had stopped themselves from particular actions because of the thought of experiencing unfair treatment, (e.g., applying for work or for training/education). Response categories ranged from 'not at all', to 'a lot' on a four-point scale and were dichotomised ('never' $v$. 'ever'). Last, those reporting any of the three domains were identified.

\section{Childhood and lifetime trauma}

Traumatic events are defined as direct, witnessing or indirect exposure to: death, threatened death, actual or threatened serious injury, or actual or threatened sexual violence (American Psychological Association (APA), 2013). Events were asked about either before age 16 years or over the lifetime and were selected using a combination of different checklist measurements from the literature on stressful experiences relevant to inner city populations (Turner \& Lloyd, 1995; Meyer, 2003). Three events before age 16 years (e.g., sexual abuse) and six lifetime potentially traumatic events were asked about (e.g., witnessing violence or murder) (Frissa et al. 2013). Response categories were binary (yes/no). The total number of childhood and lifetime experiences was summed.

Coping

Strategies to cope with perceived unfair treatment were assessed with measures adapted from the Perceived Racism Scale (McNeilly et al. 1996) by asking participants how they coped with unfair treatment in general rather than racism. Participants were asked to rate how often they used a list of nine mechanisms to cope with unfair treatment such as, 'avoiding the situation'. Responses were scored $0-3$ on a four-point scale and binary variables created for each mechanism ('never/rarely' $v$. 'some of the time/most of the time'). Additionally, the categories of 'drink alcohol', 'smoke', 'eat fatty/sweet foods' and 'exercise' were combined into a 'health-related' coping strategy and a binary variable was created (median and below/ above median of the total score).

Mental health, substance use and well-being

Common mental disorder (CMD) symptoms were assessed by the Revised Clinical Interview Schedule (CIS-R, Lewis et al. 1992), a structured interview that asks about 14 symptom domains such as fatigue, anxiety and depression. Total scores of 12 or more are conventionally used to indicate overall presence of CMD (McManus et al. 2009). Well-being was measured using the Shortened Warwick-Edinburgh Mental Well-being Scale (Tennant et al. 2007) which evaluates various aspects of positive mental health over the past fortnight, using seven positively worded items such as, ' $\mathrm{I}$ ' 'have been feeling optimistic about the future'. Responses were measured on a five-point scale ranging from 'none of the time' to 'all of the time'. Scores were summed and used as a continuous variable - a greater score indicated more positive wellbeing and were recoded such that the lowest score was zero. The Alcohol Use Disorders Identification test (Babor et al. 2001) identified 'harmful alcohol use', corresponding to the scores of 16 or more (McManus et al. 2009). Illicit drug use was assessed by reported use of 11 substances in the past year. Lifetime suicidal ideation was assessed in SELCOH I with the following question, 'have you ever thought of taking your own life, even if you would not really do it?' Responses were binary (yes/no).

\section{Statistical analyses}

Analyses were conducted in STATA 11 (StataCorp, 2009). 'Survey commands' were used to estimate prevalence and associations to generate robust standard errors. Analyses accounted for study design, including clustering by household and weights to account for within household non-response and sample attrition between SELCoH I and SELCoH II.

To test the first hypothesis, Pearson's $\chi^{2}$ with Rao \& Scott corrections for $\chi^{2}$ tests using complex survey data (Rao \& Scott, 1984) were used to compare the prevalence of mental health and substance use outcomes by sexual orientation and multivariate logistic regression analyses were run to test the strength of the relationship adjusting for socio-demographic differences in age, gender, ethnicity, marital status and educational attainment.

To test the second hypothesis multivariate logistic regression models were run to assess whether any relationship between health outcomes and sexual orientation might be accounted for by self-reported experiences of discrimination, childhood and lifetime trauma. 
For the third hypothesis, mediation by coping was considered if coping was associated both with sexual orientation and with health/substance use outcomes, and if, when added to regression models, accounted for part or all of the association between sexual orientation on health net of adverse experiences. Due to caution around collinearity, health-related coping strategies were analysed separately. Actual numbers, weighted prevalences, $p$-values, odds ratios and 95\% confidence intervals (CI) are presented.

For the fourth hypothesis, and in line with previous analyses using SELCOH I (Hatch et al. 2011), data from SELCoH II and national 2007 APMS were combined to make direct comparisons across samples in logistic regression models adjusted for age (continuous), ethnicity (white/non-white), education (General Certificate of Secondary Education (GCSE) level or below/A-level or above), marital status (in relationship/ not in relationship) and gender. The odds of CMD (CIS-R 12+), harmful alcohol use (Alcohol Use Disorders Identification Test (AUDIT) 16+), lifetime suicidal ideation and past year drug use were compared between SELCoH and national estimates.

\section{Results}

A total of $63(5.4 \%)$ participants identified themselves as non-heterosexual, of which $n=45$ identified themselves as homosexual, $n=13$ as bi-sexual and $n=5$ as other (3.7, 1.3 and $0.4 \%$, respectively, of total sample). Four participants refused to answer the question on sexuality. In the South East London sample, compared with heterosexuals, those identifying as nonheterosexual were more likely to be male, report 'single' or 'in a relationship but not living with' relationship status and 'agnostic/atheist/no' religion (Table 1).

Non-heterosexuals reported more often experiencing everyday experiences and were more likely to report anticipated discrimination (Table 2). Several individual items of everyday and anticipated discrimination were reported by a greater proportion of nonheterosexual than heterosexual individuals, reaching statistical significance for whether people act as if they are afraid of them, not applying for work/training, and not visiting a certain area or neighbourhood. No differences were found in overall major discrimination, though a significantly higher proportion of non-heterosexuals reported ever being unfairly discouraged by a teacher or advisor from continuing their education.

Although no significant differences were found in overall childhood/lifetime trauma scores (Table 2), a greater proportion of non-heterosexuals reported each individual item - reaching statistical significance for being a victim of serious crime in their lifetime and experiencing sexual abuse before the age of 16 .

Heterosexuals more commonly reported praying to cope with unfair treatment than non-heterosexuals while a greater proportion of non-heterosexuals reported drinking alcohol and smoking cigarettes and health-related coping strategies overall (Table 3).

Hypothesis 1. Non-heterosexuals in South East London will report excess mental ill health and substance use compared with heterosexual respondents.

The proportion of non-heterosexuals reporting mental ill health and substance misuse was greater for all outcomes except well-being score (Table 4). Analyses adjusting for differences in socio-demographic characteristics indicated an excess likelihood of adverse outcomes ranging from approximately 2.8 to 3.7 -fold.

Hypothesis 2. Exposure to discrimination and childhood/lifetime trauma will account for some excess risk of mental ill health and substance use.

To minimise the number of variables added to regression models given the small number of nonheterosexuals in the sample, adjustments for overall scores were first made (model b), followed by adjustments for individual items significantly associated with sexual orientation (Table 4).

Adjusting for discrimination and lifetime/childhood trauma overall had a small to moderate impact on reducing the effect size for $\mathrm{CMD}$, as did adjusting for individual items associated with sexual orientation though non-heterosexual orientation remained associated with nearly 2.3-fold greater odds of CMD. Similarly, the effect size for lifetime suicidal ideation was moderately reduced after adjustments for individual items, particularly discrimination, although the associations in either model remained highly significant $(p<0.001)$.

Following adjustments for discrimination and childhood/lifetime trauma overall, the effect size rose from 3.30 to 4.14 , though this was accompanied by widening CIs at the upper bound. Adjustments for individual discrimination items had no impact on the effect size for harmful alcohol use, while adjustments for childhood/ lifetime trauma had a considerable impact - although the association between non-heterosexual orientation and harmful alcohol use remained significant $(p=0.024)$.

Last, the association between non-heterosexuality and drug use was attenuated by a small degree by the addition of discrimination and lifetime/childhood trauma overall. In contrast to harmful alcohol use, adjustments for individual childhood/lifetime trauma had little or no impact on the effect size while adjustments for discrimination items had a considerable impact - though again the association remained significant $(p=0.001)$. 
Table 1. Demographic and socio-economic characteristics by sexual orientation. Numbers ( $n)$, weighted percentages (\%), and p-values are shown

\begin{tabular}{|c|c|c|c|c|c|}
\hline & \multicolumn{2}{|c|}{$\begin{array}{l}\text { Heterosexual } \\
\qquad(n=978)\end{array}$} & \multicolumn{2}{|c|}{$\begin{array}{l}\text { Non-heterosexual } \\
\qquad(n=63)\end{array}$} & \multirow[b]{2}{*}{$p$} \\
\hline & $n$ & $\%$ & $n$ & $\%$ & \\
\hline Gender & & & & & $<0.001$ \\
\hline Female & 590 & 68.7 & 22 & 44.0 & \\
\hline Male & 388 & 31.4 & 41 & 56.0 & \\
\hline Age (years) & & & & & 0.060 \\
\hline $16-24$ & 122 & 13.6 & 11 & 22.8 & \\
\hline $25-34$ & 221 & 20.9 & 15 & 23.1 & \\
\hline $35-44$ & 191 & 17.5 & 12 & 16.3 & \\
\hline $45-54$ & 183 & 16.1 & 16 & 22.3 & \\
\hline $55+$ & 261 & 32.0 & 9 & 15.5 & \\
\hline Marital status & & & & & $<0.001$ \\
\hline Married/cohabiting & 539 & 52.1 & 24 & 33.4 & \\
\hline Single & 243 & 25.6 & 22 & 38.7 & \\
\hline In a relationship not living with/other & 113 & 11.2 & 13 & 21.7 & \\
\hline Divorced/widowed/separated & 83 & 11.1 & 4 & 6.3 & \\
\hline Education & & & & & 0.261 \\
\hline None/below GCSE level & 255 & 28.9 & 13 & 21.3 & \\
\hline GCSE & 179 & 18.1 & 16 & 28.0 & \\
\hline A level/vocational & 318 & 31.6 & 19 & 29.9 & \\
\hline Degree or above & 226 & 21.4 & 15 & 20.8 & \\
\hline Binary ethnicity & & & & & 0.105 \\
\hline White & 627 & 64.1 & 47 & 74.6 & \\
\hline Non-white & 351 & 35.9 & 16 & 25.4 & \\
\hline Religion & & & & & $<0.001$ \\
\hline None/agnostic/atheist & 359 & 34.8 & 37 & 59.2 & \\
\hline Any other & 619 & 65.2 & 21 & 40.8 & \\
\hline Employment status & & & & & 0.865 \\
\hline Paid employment & 594 & 55.4 & 38 & 54.3 & \\
\hline Unemployed/economically inactive & 383 & 44.6 & 25 & 45.8 & \\
\hline Housing tenure & & & & & 0.064 \\
\hline Own/shared ownership/mortgage & 378 & 38.9 & 22 & 33.5 & \\
\hline Renting & 532 & 57.0 & 34 & 55.6 & \\
\hline Rent-free/other & 38 & 4.1 & 5 & 11.0 & \\
\hline Monthly income & & & & & 0.844 \\
\hline$£ 0-420$ & 193 & 21.9 & 11 & 20.7 & \\
\hline$£ 421-928$ & 201 & 22.8 & 9 & 17.0 & \\
\hline$£ 929-1592$ & 154 & 16.5 & 11 & 18.0 & \\
\hline$£ 1593-2416$ & 156 & 14.9 & 12 & 18.6 & \\
\hline$£ 2417+$ & 254 & 23.9 & 20 & 25.8 & \\
\hline
\end{tabular}

Numbers may not add up due to missing data.

Hypothesis 3. Coping behaviour will mediate the association between sexual orientation and adverse health and substance use outcomes.

As indicated above, significant differences in coping strategies used to cope with unfair treatment were found by sexual orientation (Table 3). Above median health-related coping scores were significantly associated with each health and substance use outcome, while those who more often reported praying were less likely to meet criteria for harmful alcohol or past year drug use. Adjusting for health-related coping had very little impact on effect sizes in models adjusting for individual discrimination items, and only a slight impact on the effect size for harmful alcohol use (odds ratio, OR 3.07, 95\% CI: 1.54-6.09, data not shown). In models adjusting for individual trauma 
Table 2. Lifetime exposure to discrimination, lifetime and child trauma by sexual orientation. Numbers ( $n$ ), weighted percentages (\%), and p-values are shown

\begin{tabular}{|c|c|c|c|c|c|}
\hline & \multicolumn{2}{|c|}{$\begin{array}{l}\text { Heterosexual } \\
\qquad(n=978)\end{array}$} & \multicolumn{2}{|c|}{$\begin{array}{l}\text { Non-heterosexual } \\
\qquad(n=63)\end{array}$} & \multirow[b]{2}{*}{$p$} \\
\hline & $n$ & $\%$ & $n$ & $\%$ & \\
\hline Any experience of major discrimination & 471 & 47.2 & 32 & 54.6 & 0.272 \\
\hline \multicolumn{6}{|l|}{ Ever experienced: } \\
\hline Fired unfairly & 103 & 10.5 & 7 & 11.7 & 0.771 \\
\hline Not hired unfairly & 128 & 12.6 & 8 & 13.4 & 0.863 \\
\hline Denied promotion unfairly & 97 & 9.8 & 7 & 11.7 & 0.645 \\
\hline Unfair treatment by police & 141 & 12.8 & 9 & 16.3 & 0.463 \\
\hline Unfair treatment by court system & 51 & 5.0 & 3 & 6.8 & 0.581 \\
\hline Discouraged from continuing education & 108 & 11.1 & 12 & 22.1 & 0.023 \\
\hline Prevented from moving into a neighbourhood & 17 & 1.9 & 1 & 1.7 & 0.094 \\
\hline Neighbours made life difficult & 84 & 8.5 & 5 & 8.6 & 0.981 \\
\hline Unfairly treated by bank & 43 & 4.1 & 1 & 2.2 & 0.518 \\
\hline Received worse service than others & 78 & 7.8 & 6 & 10.1 & 0.534 \\
\hline Unfairly treated in medical care & 60 & 6.6 & 4 & 7.6 & 0.766 \\
\hline Unfairly treated on public transport & 80 & 8.4 & 7 & 12.6 & 0.289 \\
\hline Everyday discrimination (median or more) & 554 & 54.3 & 48 & 74.9 & 0.003 \\
\hline \multicolumn{6}{|l|}{ Experienced fairly often/often: } \\
\hline Treated with less courtesy & 46 & 4.4 & 4 & 6.2 & 0.512 \\
\hline Treated with less respect & 38 & 3.8 & 4 & 7.1 & 0.244 \\
\hline Received poorer service & 23 & 2.4 & 1 & 2.2 & 0.919 \\
\hline People act as if not smart & 54 & 5.6 & 4 & 8.1 & 0.446 \\
\hline People act as if afraid of me & 16 & 1.8 & 3 & 5.9 & 0.045 \\
\hline People act as if I am dishonest & 14 & 1.5 & 2 & 5.2 & 0.073 \\
\hline People act as if better than me & 78 & 8.0 & 7 & 13.8 & 0.152 \\
\hline Called names or insulted & 21 & 2.2 & 2 & 4.3 & 0.352 \\
\hline Threatened or harassed & 13 & 1.5 & 1 & 1.7 & 0.880 \\
\hline Followed in stores & 31 & 3.1 & 1 & 2.2 & 0.732 \\
\hline Any experience of anticipated discrimination & 262 & 26.2 & 28 & 45.5 & 0.002 \\
\hline \multicolumn{6}{|l|}{ Ever experienced: } \\
\hline Not applied for work or training & 130 & 12.8 & 14 & 23.3 & 0.022 \\
\hline Not contacted health services & 39 & 4.3 & 4 & 7.2 & 0.291 \\
\hline Not visited a certain area & 167 & 16.3 & 18 & 28.8 & 0.018 \\
\hline Any experience of lifetime trauma & 603 & 61.7 & 44 & 73.6 & 0.076 \\
\hline \multicolumn{6}{|l|}{ Ever experienced: } \\
\hline Witnessed violence & 377 & 36.9 & 28 & 48.2 & 0.099 \\
\hline Victim of a serious crime & 340 & 35.4 & 31 & 52.0 & 0.012 \\
\hline Injured with weapon & 82 & 7.7 & 7 & 12.8 & 0.179 \\
\hline Physical or sexual abuse & 314 & 31.5 & 24 & 40.8 & 0.145 \\
\hline Any experience of childhood trauma & 252 & 25.4 & 20 & 32.5 & 0.224 \\
\hline \multicolumn{6}{|l|}{ Ever experienced: } \\
\hline Physical abuse & 234 & 23.1 & 18 & 29.1 & 0.297 \\
\hline Sexual abuse & 42 & 4.8 & 9 & 15.7 & $<0.001$ \\
\hline
\end{tabular}

items, there was very little/no impact of adjustment for health-related coping. Adjusting for praying in both the trauma and discrimination models reduced effect sizes from a small to moderate degree for suicidal ideation, alcohol and drug use; and, rendered the association with harmful alcohol use non-significant (OR 2.19, 95\% CI: 0.97-4.91, $p=0.058$, data not shown).
Hypothesis 4. The elevated odds of mental ill health and substance use among non-heterosexuals will be less apparent in South East London than nationally.

CMD, lifetime suicidal ideation, harmful alcohol and past year drug use in the SELCoH sample was compared with the national sample among heterosexuals and non-heterosexuals separately (Table 5). 
Table 3. Mechanisms used some/most of the time to cope with unfair treatment by sexual orientation. Numbers ( $n$ ), weighted percentages $(\%)$, and p-values are shown

\begin{tabular}{|c|c|c|c|c|c|}
\hline & \multicolumn{5}{|c|}{ Coping with unfair treatment } \\
\hline & \multicolumn{2}{|c|}{$\begin{array}{l}\text { Heterosexual } \\
\qquad(n=978)\end{array}$} & \multicolumn{2}{|c|}{$\begin{array}{l}\text { Non-heterosexual } \\
\qquad(n=63)\end{array}$} & \multirow[b]{2}{*}{$p$} \\
\hline & $n$ & $\%$ & $n$ & $\%$ & \\
\hline Exercise & 261 & 26.9 & 21 & 33.9 & 0.254 \\
\hline Eat sweets/fatty foods & 246 & 26.8 & 19 & 32.9 & 0.298 \\
\hline Drink alcohol & 231 & 23.3 & 22 & 36.6 & 0.027 \\
\hline Smoke cigarettes & 159 & 16.6 & 16 & 27.8 & 0.029 \\
\hline Health-related coping (above median) & 689 & 69.1 & 51 & 81.9 & 0.036 \\
\hline Talking about problem & 700 & 73.9 & 44 & 70.8 & 0.603 \\
\hline Pray & 280 & 31.0 & 10 & 15.2 & 0.008 \\
\hline Avoid the situation & 590 & 62.8 & 44 & 73.2 & 0.103 \\
\hline Do something about it & 726 & 76.5 & 50 & 82.8 & 0.274 \\
\hline Accept situation & 572 & 60.4 & 36 & 58.7 & 0.795 \\
\hline
\end{tabular}

Compared with the national sample, among heterosexuals, the SELCoH sample experienced higher levels of all outcomes considered, with elevated odds between 1.5 and 2.6-fold. Among non-heterosexuals, the SELCoH sample also had increased odds of all outcomes and the excess morbidity was greater than that estimated among heterosexuals, with elevated odds between 2.2 and nearly 5 -fold.

\section{Discussion}

This study tested four hypotheses. The hypothesis that the mental health of non-heterosexual individuals would be poorer than heterosexuals was supported, with the former being associated with 2.8 to 3.7-fold greater odds of adverse outcomes. The hypothesis that some of this relationship would be accounted for by excess exposure to discrimination and childhood/ lifetime traumatic events was partially supported. Adding individual exposure items associated with sexual orientation to regression models attenuated effect sizes from a small to moderate degree but all significant associations remained. The hypothesis that differences in coping strategies used to deal with unfair treatment might mediate the association between sexual orientation and health/substance use outcomes was only partially supported. In the trauma model, adjustment for praying but not health-related coping fully mediated the association between sexual orientation and harmful alcohol use. Last, the hypothesis that the disparity in mental health by sexual orientation found in our inner city sample would be less apparent than that found in a national sample was not supported. The South East London sample not only had poorer mental health and substance use outcomes overall, the discrepancy was also larger among non-heterosexuals.

\section{Mental ill health and sexual orientation}

Elevated rates of mental ill health and substance use among sexual minorities have been well documented. Our estimated effect sizes are larger than previously reported (King et al. 2008; Chakraborty et al. 2011), though small numbers of non-heterosexuals in the current sample mean that the CIs may overlap with previous findings.

\section{Discrimination and traumatic life experiences}

Two processes proposed to be linked to minority stress among non-heterosexuals were addressed: external stressful events or situations, and anticipation and vigilance for these types of experiences. We hypothesised that a greater likelihood of exposure to such events would partly account of the elevated psychological morbidity. While adjusting for individual items associated with sexual orientation reduced effect sizes to a degree; all significant associations remained. Residual confounding associated with discrimination is likely though, since we did not specifically ask about discrimination on the grounds of sexual orientation and the measures were designed to examine discrimination on the grounds of other factors - racism and serious mental illness. Also, individuals do not always occupy a social status in isolation and may 
Table 4. Adjusted associations between sexual orientation and mental health, substance use and well-being. Odd ratios (OR) and 95\% confidence intervals (CI) are shown

\begin{tabular}{|c|c|c|c|c|c|c|}
\hline & & $n(\%)$ & Model A & Model B & Model C & Model D \\
\hline \multirow[t]{2}{*}{ Well-being (coefficient) ${ }^{a}$} & $\mathrm{H}$ & $25.1(24.8-25.4)$ & 1.00 & 1.00 & 1.00 & 1.00 \\
\hline & $\mathrm{NH}$ & $23.7(22.3-25.0)$ & $-1.23(-2.51$ to 0.48$)$ & $-0.85(-2.12$ to 0.41$)$ & $-0.87(-2.13$ to 0.39$)$ & $-0.97(-2.24$ to 0.29$)$ \\
\hline \multirow[t]{2}{*}{ Common mental disorder ${ }^{\mathrm{b}}$} & $\mathrm{H}$ & $204(22.0)$ & 1.00 & 1.00 & 1.00 & 1.00 \\
\hline & $\mathrm{NH}$ & $24(42.1)$ & $2.78(1.56-4.97)^{* * *}$ & $2.32(1.23-4.40)^{* *}$ & $2.39(1.31-4.37)^{* *}$ & $2.27(1.24-4.15)^{* *}$ \\
\hline \multirow[t]{2}{*}{ Suicidal ideation } & $\mathrm{H}$ & $191(20.0)$ & 1.00 & 1.00 & 1.00 & 1.00 \\
\hline & $\mathrm{NH}$ & $31(51.5)$ & $3.71(2.10-6.55)^{* * *}$ & $3.66(1.99-6.70)^{* * *}$ & $3.16(1.82-5.48)^{* * *}$ & $3.33(1.80-6.15)^{* * *}$ \\
\hline \multirow[t]{2}{*}{ Harmful alcohol use ${ }^{c}$} & $\mathrm{H}$ & $41(3.9)$ & 1.00 & 1.00 & 1.00 & 1.00 \\
\hline & $\mathrm{NH}$ & $12(18.8)$ & $3.30(1.62-6.74)^{* * *}$ & $4.14(1.90-9.02)^{* * *}$ & $3.18(1.59-6.36)^{* *}$ & $2.50(1.13-5.52)^{*}$ \\
\hline \multirow[t]{2}{*}{ Past year drug use ${ }^{\mathrm{d}}$} & $\mathrm{H}$ & $167(15.9)$ & 1.00 & 1.00 & 1.00 & 1.00 \\
\hline & $\mathrm{NH}$ & $32(50.6)$ & $3.66(1.87-7.13)^{* * *}$ & $3.46(1.77-6.74)^{* * *}$ & $3.20(1.65-6.22)^{* *}$ & $3.69(1.84-7.42)^{* * *}$ \\
\hline
\end{tabular}

$\mathrm{H}$, heterosexual; $\mathrm{NH}$, non-heterosexual.

Model A adjusted for age (continuous), gender, educational attainment, ethnicity, marital status. Model B as model A, additionally adjusted for major, everyday and anticipated discrimination and childhood and lifetime trauma overall. Model C as model A, additionally adjusted for being discouraged from education, people act as if they are afraid of me, not applying for work and not visiting certain areas for fear of being treated unfairly. Model D as model A, additionally adjusted for childhood sexual abuse and whether ever been a victim of a serious crime.

aShortened Warwick-Edinburgh mental well-being scale (continuous).

${ }^{\mathrm{b}}$ Revised Clinical Interview Schedule, cut-off $12+$.

${ }^{c}$ Alcohol Use Disorders Identification test, cut-off $16+$.

${ }^{\mathrm{d}}$ Includes: cannabis, cocaine, metamphetamine, Khat, amphetamines, crack, tranquilisers, heroin, ecstasy and lysergic acid diethylamide (LSD).

${ }^{*} p \leq 0.05,{ }^{* *} p \leq 0.01,{ }^{* * *} p \leq 0.001$. 
Table 5. Comparison of substance misuse and mental health outcomes between South East London Community Health survey (SELCoH) and Adult Psychiatric Morbidity Survey 2007 (APMS) England/London samples by sexuality. Numbers (n), weighted percentages (\%), odds Ratios (OR) and 95\% confidence intervals (CI) are shown

\begin{tabular}{|c|c|c|c|c|c|}
\hline & & \multicolumn{2}{|c|}{ Heterosexual } & \multicolumn{2}{|c|}{ Non-heterosexual } \\
\hline & & $n(\%)$ & OR $(95 \% \mathrm{CI})^{+}$ & $n(\%)$ & OR $(95 \% \mathrm{CI})^{\mathrm{a}}$ \\
\hline \multirow[t]{2}{*}{ Common mental disorder ${ }^{\mathrm{b}}$} & SELCoH & $204(22.0)$ & $1.60(1.31-1.96)^{* * *}$ & $24(42.1)$ & $2.94(1.66-5.21)^{* * *}$ \\
\hline & APMS & $1039(14.4)$ & 1.00 & $128(22.7)$ & 1.00 \\
\hline \multirow{2}{*}{ Suicidal ideation } & SELCoH & $191(20.0)$ & $1.53(1.25-1.88)^{* * *}$ & $31(51.5)$ & $2.62(1.48-4.64)^{* * *}$ \\
\hline & APMS & 1109 (15.6) & 1.00 & $154(31.7)$ & 1.00 \\
\hline \multirow[t]{2}{*}{ Harmful alcohol use $e^{c}$} & SELCoH & $41(3.9)$ & $1.83(1.25-2.68)^{* *}$ & $12(18.8)$ & $2.24(1.03-4.87)^{*}$ \\
\hline & APMS & $200(3.3)$ & 1.00 & $41(10.0)$ & 1.00 \\
\hline \multirow[t]{2}{*}{ Past year drug use ${ }^{\mathrm{d}}$} & SELCoH & $167(15.9)$ & $2.64(2.05-3.40)^{* * *}$ & $32(50.6)$ & $4.99(2.59-9.61)^{* * *}$ \\
\hline & APMS & $430(8.2)$ & 1.00 & $82(19.3)$ & 1.00 \\
\hline
\end{tabular}

aAdjusted model with combined comparable data from both studies; including gender, age (continuous), binary ethnicity, binary education, binary marital status.

${ }^{\mathrm{b}}$ Revised Clinical Interview Schedule, cut-off $12+$.

${ }^{c}$ Alcohol Use Disorders Identification test, cut-off $16+$.

${ }^{\mathrm{d}}$ Includes: cannabis, cocaine, amphetamines, crack, tranquilisers, heroin, ecstasy and LSD.

${ }^{*} p \leq 0.05,{ }^{* *} p \leq 0.01,{ }^{* * *} p \leq 0.001$.

experience discrimination of any form - major, perceived or anticipated - based on other factors. It is important to utilise an 'intersectional approach' to understand mental ill health in minority individuals, and to consider interdependencies between social statuses, risk and protective factors (Bostwick et al. 2014).

The finding that sexual minorities are more likely to report childhood sexual abuse is consistent with the literature (Friedman et al. 2011) and childhood sexual abuse is robustly associated with psychological ill health (e.g. Paolucci et al. 2001). In the current study, adjustments for childhood sexual abuse demonstrated that it may contribute to the excess risk of mental ill health - with a particularly notable influence on harmful alcohol use.

\section{Coping}

Although coping behaviours were associated both with sexual orientation and health outcomes, adjusting for them attenuated effect sizes from a small to moderate degree and this was more apparent for praying than for health-related coping. Mediation of the association between sexual orientation and alcohol use by praying is likely to be accounted for by religious differences in alcohol use as significantly greater heterosexuals than non-heterosexuals reported any religion. Excess alcohol and drug use among sexual minorities is well documented (King et al. 2008; Green \& Feinstein, 2012) and sexual minorities are more likely to have social-networks based around activities involving drinking and drug use
(Green \& Feinstein, 2012) - with implications for social norms and influence (Berkman et al. 2000). Non-heterosexuals may be both more likely to use substances in general and more likely to turn to substances in response to stress. The coping behaviours included here may not adequately frame the general psychological processes triggered by stress; further work should include a broader range of coping strategies. For example, rumination is a coping strategy previously found to be common among non-heterosexuals and has been identified as an underlying mechanism behind excess CMD (e.g., Hatzenbuehler et al. 2008).

\section{Additional explanations for excess mental ill health}

Two other processes linked to minority stress not considered here might account further for these inequalities. Both internalised homophobia (internalisation of negative cultural views) and concealment of sexual orientation are associated with poorer mental health (Williamson, 2000; Newcomb \& Mustanski, 2010). The degree to which individuals internalise homophobic beliefs or conceal their identity may depend on other factors also linked to mental health, such as prevalent social norms and availability of social support. Concealment may be compounded by having additional minority statuses; in the current study $25 \%$ of non-heterosexuals were non-white and previous research has found ethnic differences in internalised homophobia and concealment (e.g., Rosario et al. 2004). Additionally, this study did not explore the impact of the context of social support, which 
may influence mental health and substance misuse among non-heterosexuals (Nadal et al. 2011; Green \& Feinstein, 2012; Buttram \& Kurtz, 2013).

\section{Local v. national estimates}

Higher rates of mental ill health and drug use in the South East London sample overall has been previously reported (Hatch et al. 2012). Our finding that this excess was more pronounced among non-heterosexuals contradicts our hypothesis. Although CIs were wider in the non-heterosexual sample, the finding could also reflect differences in experiences within London, with variation in social density and/or acceptance of sexual minorities. A lack of data monitoring sexual orientation precludes examination of within-city comparisons.

Other explanations may be linked to findings that the UK non-heterosexuals living in London are most likely to worry about being the victim of crime and to have been a victim of a homophobic hate crime (Guasp, 2012). This may increase expectations of adverse events, perhaps triggering use of anticipatory vigilance as a coping style (LaVeist et al. 2014). Furthermore, the area contains a greater proportion of individuals of Black Caribbean and Black African ethnicity. Non-heterosexuals within these communities will be at risk of experiencing additional mental health implications of racism as well as potentially more negative attitudes towards homosexuality (Glick \& Golden, 2010). Evidence from a large US study of LGB youth reported a strong association between an objective measure of social environmental influences (specifically regarding supporting sexual minorities within communities) and suicide attempts, such that the risk of attempting suicide among LGB youth was approximately $20 \%$ higher in unsupportive than supportive social environments (Hatzenbuehler, 2011).

\section{Strengths and limitations}

This study uses a representative sample within a local area, examines a broad array of factors potentially linked to excess mental ill health among sexual minorities, and the linkage to national data facilitated the cross-validation of our estimates. Other strengths are the inclusion of three types of discrimination and the investigation of discrimination and trauma in the same sample. No studies have looked at the role of coping, or have compared urban with national data.

The main limitation is the small sample of nonheterosexuals included in analyses constraining the power of analyses and increasing the likelihood of Type II errors. Also, previous work indicates significant differences within and across minority groups (Saewyc et al. 2007; King et al. 2008; Marshal et al.
2011; Burns et al. 2015). Due to small numbers we were unable to conduct sub-group analyses across gender and sexual orientation. Last, we may have underestimated the prevalence of non-heterosexuality by asking only about the identity component of sexuality and by asking respondents face-to-face (Savin-Williams, 2006). However, the proportion of non-heterosexuals in our sample was higher than recent UK census rates for both the UK $(1.6 \%)$ and London (3.2\%) (ONS, 2014).

\section{Clinical and research implications}

A lack of locally available evidence about the needs and healthcare experiences of non-heterosexuals may account for the relatively low priority of such groups afforded by commissioners, policy-makers and clinicians (Winter, 2012). As such individuals are more likely to seek help from a health professional (King et al. 2003; Chakraborty et al. 2011) our findings underpin the importance of supporting health service provision and research in this area. For instance, to identify the best ways to promote health professionals' awareness of structural and minority stressors affecting LGB individuals, and any potential barriers to help-seeking. Further work is also needed to measure the quality of mental health care that LGB individuals receive and to understand whether existing psychological and social mental health interventions work just as well for LGB people as for heterosexuals given the unique stressors affecting this group. Previous research has highlighted the role of marginalisation and migration on mental health outcomes within non-heterosexual individuals in the USA (Lewis, 2014), but there is no UK research. Research into differences in life trajectories and migration patterns by sexual orientation may help us to understand regional differences in outcomes.

\section{Acknowledgements}

This research was supported by the Biomedical Research Nucleus data management and informatics facility at South London and Maudsley NHS Foundation Trust, which is funded by the National Institute for Health Research (NIHR) Mental Health Biomedical Research Centre at South London and Maudsley NHS Foundation Trust and King's College London and a joint infrastructure grant from Guy's and St Thomas' Charity and the Maudsley Charity.

\section{Financial Support}

B. G. receives funding from an Economic and Social Research Council Studentship. B. G., S. L. H. and 
M. H. receive salary support from the National Institute for Health Research (NIHR) Mental Health Biomedical Research Centre at South London and Maudsley NHS Foundation Trust and King's College London. This work was partly funded by the Economic and Social Research Council [grant number RES-177-25-0015]. The funders did not have a role in the study design; collection, analysis or interpretation of data; the writing of the manuscript; or in the decision to submit the manuscript for publication.

\section{Conflicts of Interest}

None.

\section{Ethical Standards}

The authors assert that all procedures contributing to this work comply with the ethical standards of the relevant national and institutional committees on human experimentation and with the Helsinki Declaration of 1975, as revised in 2008. Ethical approval for SELCoH I was received from the King's College London Research Ethics Committee for non-clinical research populations (reference CREC/07/08-152) and for SELCoH II was received from the King's College London Psychiatry, Nursing and Midwifery Research Ethics Committee (PNM/10/11-106).

\section{References}

American Psychological Association (APA) (2013). Diagnosticand Statistical Manual of Mental Disorders, 5th edn. APA: Washington, DC.

Austin SB, Jun HJ, Jackson B, Spiegelman D, Rich-Edwards J, Corliss HL, Wright RJ (2008). Disparities in child abuse victimization in lesbian, bisexual, and heterosexual women in the Nurses' Health Study II. Journal of Women's Health 17, 597-606.

Babor TF, Higgins-Biddle JC, Saunders JB, Monteiro MG (2001). The Alcohol Use Disorders Identification Test. Guidelines for Use in Primary Care, 2. World Health Organisation: Geneva.

Balsam KF, Rothblum ED, Beauchaine TP (2005). Victimization over the life span: a comparison of lesbian, gay, bisexual, and heterosexual siblings. Journal of Consulting and Clinical Psychology 73, 477-487.

Berkman LF, Glass T, Brissette I, Seeman TE (2000). From social integration to health: Durkheim in the new millennium. Social Science and Medicine 51, 843-857.

Bostwick WB, Meyer I, Aranda F, Russell S, Hughes T, Birkett M, Mustanski B (2014). Mental health and suicidality among racially/ethnically diverse sexual minority youths. American Journal of Public Health 104, 1129-1136.

Burns MN, Ryan DT, Garofalo R, Newcomb ME, Mustanski B (2015). Mental health disorders in young urban sexual minority men. Journal of Adolescent Health 56, 52-58.
Buttram ME, Kurtz SP (2013). Risk and protective factors associated with gay neighborhood residence. American Journal of Men's Health 7, 110-118.

Chakraborty A, McManus S, Brugha TS, Bebbington P, King M (2011). Mental health of the non-heterosexual population of England. British Journal of Psychiatry 198, 143-148.

Cochran SD, Mays VM, Sullivan JG (2003). Prevalence of mental disorders, psychological distress, and mental health services use among lesbian, gay, and bisexual adults in the United States. Journal of Consulting and Clinical Psychology 71, 53-61.

Friedman MS, Marshal MP, Guadamuz TE, Wei C, Wong CF, Saewyc EM, Stall R (2011). A meta-analysis of disparities in childhood sexual abuse, parental physical abuse, and peer victimization among sexual minority and sexual nonminority individuals. American Journal of Public Health 101, 1481-1494.

Frissa S, Hatch S, Gazard B, Fear N, Hotopf M (2013). Trauma and current symptoms of PTSD in a South East London community. Social Psychiatry and Psychiatric Epidemiology 48, 1199-1209.

Glick SN, Golden MR (2010). Persistence of racial differences in attitudes toward homosexuality in the United States. Journal of Acquired Immune Deficiency Syndrome 55, 516-523.

Greater London Authority (GLA) (2011). Assessment of GLA Impact on Lesbian, Gay And Bisexual Equality. Retrieved 15 June 2014 from http://www.london.gov.uk/sites/default/ files/Assessment $\% 20$ of $\% 20$ GLA $\% 20$ impact $\% 20$ on $\% 20$ LGB $\% 20$ equality.pdf.

Green KE, Feinstein BA (2012). Substance use in lesbian, gay, and bisexual populations: an update on empirical research and implications for treatment. Psychology of Addictive Behaviors 26, 265-278.

Guasp A (2012). The School Report: the Experiences of Gay Young People in Britain's Schools in 2012. Stonewall: UK.

Guasp A, Gammon A, Ellison G (2013). Homophobic Hate Crime: the Gay British Crime Survey 2013. Stonewall: UK.

Hatch S, Frissa S, Verdecchia M, Stewart R, Fear N, Reichenberg A, Morgan C, Kankulu B, Clark J, Gazard B, Medcalf R, the SELCoH study team, Hotopf M (2011). Identifying socio-demographic and socioeconomic determinants of health inequalities in a diverse London community: the South East London Community Health (SELCoH) study. BMC Public Health 11, 861.

Hatch SL, Woodhead C, Frissa S, Fear NT, Verdecchia M, Stewart R, Reichenberg A, Morgan C, Bebbington P, McManus S, Brugha T, Kankulu B, Clark JL, Gazard B, Medcalf R, Hotopf M, the SELCoH study team (2012). Importance of thinking locally for mental health: data from cross-sectional surveys representing South East London and England. PLoS ONE 7, e48012. doi: 10.1371/journal. pone. 0048012 .

Hatzenbuehler ML (2009). How does sexual minority stigma "get under the skin"? A psychological mediation framework. Psychological Bulletin 135, 707-730.

Hatzenbuehler ML (2011). The social environment and suicide attempts in lesbian, gay, and bisexual youth. Pediatrics 127, 896-903. 
Hatzenbuehler ML, McLaughlin KA, Nolen-Hoeksema S (2008). Emotion regulation and internalizing symptoms in a longitudinal study of sexual minority and heterosexual adolescents. Journal of Child Psychology and Psychiatry 49, 1270-1278

Hatzenbuehler ML, Keyes KM, McLaughlin KA (2011). The protective effects of social/contextual factors on psychiatric morbidity in LGB populations. International Journal of Epidemiology 40, 1071-1080.

Herek GM, McLemore KA (2013). Sexual prejudice. Annual Review of Psychology 64, 309-333.

Kessler RC, Mickelson KD, Williams DR (1999). The prevalence, distribution, and mental health correlates of perceived discrimination in the United States. Journal of Health and Social Behavior 40, 208-230.

King M, McKeown E, Warner J, Ramsay A, Johnson K, Cort C, Wright L, Blizard R, Davidson O (2003). Mental health and quality of life of gay men and lesbians in England and Wales: controlled, cross-sectional study. British Journal of Psychiatry 183, 552-558.

King M, Semlyen J, Tai S, Killaspy H, Osborn D, Popelyuk D, Nazareth I (2008). A systematic review of mental disorder, suicide, and deliberate self harm in lesbian, gay and bisexual people. BMC Psychiatry 8, 70.

LaVeist TA, Thorpe RJ, Pierre G, Mance GA, Williams DR (2014). The relationships among vigilant coping style, race, and depression. Journal of Social Issues 70, 241-255.

Lewis G, Pelosi AJ, Araya R, Dunn G (1992). Measuring psychiatric disorder in the community: a standardized assessment for use by lay interviewers. Psychological Medicine 22, 465-486.

Lewis NM (2014). Rupture, resilience, and risk: relationships between mental health and migration among gay-identified men in North America. Health and Place 27, 212-219.

Marshal MP, Dietz LJ, Friedman MS, Stall R, Smith HA, McGinley J, Thoma BC, Murray PJ, D'Augelli AR, Brent DA (2011). Suicidality and depression disparities between sexual minority and heterosexual youth: a meta-analytic review. Journal of Adolescent Health 49, 115-123.

McManus S, Meltzer H, Brugha T, Bebbington P, Jenkins R (2009). Adult Psychiatric Morbidity in England, 2007: Results of a Household Survey. The Health \& Social Care Information Centre, Social Care Statistics: UK.

McNeilly MD, Anderson NB, Armstead CA, Clark R, Corbett M, Robinson EL, Pieper CF, Lepisto EM (1996). The perceived racism scale: a multidimensional assessment of the experience of white racism among African Americans. Ethnicity and Disease 6, 154-166.

Meyer IH (2003). Prejudice, social stress, and mental health in lesbian, gay, and bisexual populations: conceptual issues and research evidence. Psychological Bulletin 129, 674-697.

Nadal KL, Wong Y, Issa M-A, Meterko V, Leon J, Wideman M (2011). Sexual orientation microaggressions: processes and coping mechanisms for lesbian, gay, and bisexual Individuals. Journal of LGBT Issues in Counseling 5, 21-46.

Newcomb ME, Mustanski B (2010). Internalized homophobia and internalizing mental health problems: a meta-analytic review. Clinical Psychology Review 30, 1019-1029.
Nodin N, Peel E, Tyler A, Rivers I (2015). The RaRE research reportt: LGB\&T mental health-risk and resilience explored. PACE Health. Retrieved 15 June 2015 from http://www. pacehealth.org.uk/files/1614/2978/0087/RARE_Research_ Report_PACE_2015.pdf.

Office for National Statistics (ONS) (2013). Key Findings from the Integrated Household Survey: January 2012 to December 2012. Retrieved 15 June 2014 from http://www.ons.gov.uk/ ons/dcp171778_329407.pdf.

Office for National Statistics (ONS) (2014). Integrated Household Survey, January to December 2013: Experimental Statistics. Retrieved 15 June 2015 from http://www.ons.gov. uk/ons/rel/integrated-household-survey/integrated-householdsurvey/january-to-december-2013/stb-intergrated-household. html.

Paolucci EO, Genius ML, Violato C (2001). A meta-analysis of the published research on the effects of child sexual abuse. Journal of Psychology 135, 17-36.

Rao JN, Scott AJ (1984). On chi-squared tests for multiway contingency tables with cell proportions estimated from survey data. Annals of Statistics, 46-60.

Robinson JP, Espelage DL, Rivers I (2013). Developmental trends in peer victimization and emotional distress in LGB and heterosexual youth. Pediatrics 131, 423-430.

Rosario M, Schrimshaw EW, Hunter J (2004). Ethnic/racial differences in the coming-out process of gay, lesbian, and bisexual youths: a comparison of sexual identity development over time. Cultural Diversity and Ethnic Minority Psychology 10, 215-228.

Saewyc EM, Skay CL, Hynds P, Pettingell S, Bearinger LH, Resnick MD, Reis E (2007). Suicidal ideation and attempts in North American school-based surveys: are bisexual youth at increasing risk? Journal of LGBT Health Research 3, 25-36.

Savin-Williams RC (2006). Who's gay? Does it matter? Current Directions in Psychological Science 15, 40-44.

StataCorp (2009). Stata Statistical Software: Release 11. StataCorp LP: College Station, TX.

Tennant R, Hiller L, Fishwick R, Platt S, Joseph S, Weich S, Parkinson J, Secker J, Stewart-Brown S (2007). The Warwick-Edinburgh Mental Well-being Scale (WEMWBS): development and UK validation. Health and Quality of LifeOutcomes 5, 63.

Thornicroft G, Brohan E, Rose D, Sartorius N, Leese M, INDIGO Study Group (2009). Global pattern of experienced and anticipated discrimination against people with schizophrenia: a cross-sectional survey. Lancet 373 , 408-415.

Turner RJ, Lloyd DA (1995). Lifetime traumas and mental health: the significance of cumulative adversity. Journal of Health and Social Behaviour 36, 360-376.

Williams DR, Yan Yu, Jackson JS, Anderson NB (1997). Racial differences in physical and mental health: socio-economic status, stress and discrimination. Health Psychology 2, 335-351.

Williamson IR (2000). Internalized homophobia and health issues affecting lesbians and gay men. Health Education Research 15, 97-107.

Winter A (2012). LGBT Communities - a Summary for Joint Strategic Needs Assessment. Lesbian \& Gay Foundation: UK. 